\title{
MEDITERRANEAN DIET MODULATES THE EFFECT OF rS1761667 IN THE CD36 GENE ON FFA CONCENTRATION AND BMI IN A HIGH CARDIOVASCULAR RISK POPULATION
}

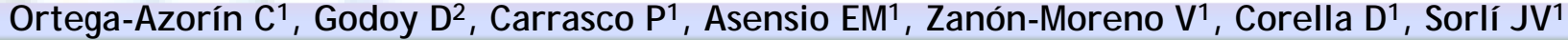

1: Department of Preventive Medicine. School of Medicine. University of Valencia and CIBERobn. Valencia. Spain 2: Internal Medicine Service. University General Hospital of Valencia. Valencia. Spain

\section{INTRODUCTION AND OBJ ECTIVE}

CD36 is a scavenger receptor that facilitates the membrane transport of long chain fatty acids into muscle and adipose tissue (Fig.1). Polymorphisms in this gene have been related to abnormal serum fatty acids and obesityrelated phenotypes with inconsistent results. Gene-diet interactions could modulate these associations. Our aim was to study whether a common functional variant (rs1761667) in this gene will associate with anthropometric variables and plasma free fatty acids (FFA) as well as the modulation by the adherence to the Mediterrranean diet (MD) in a high cardiovascular risk (CVR) population.

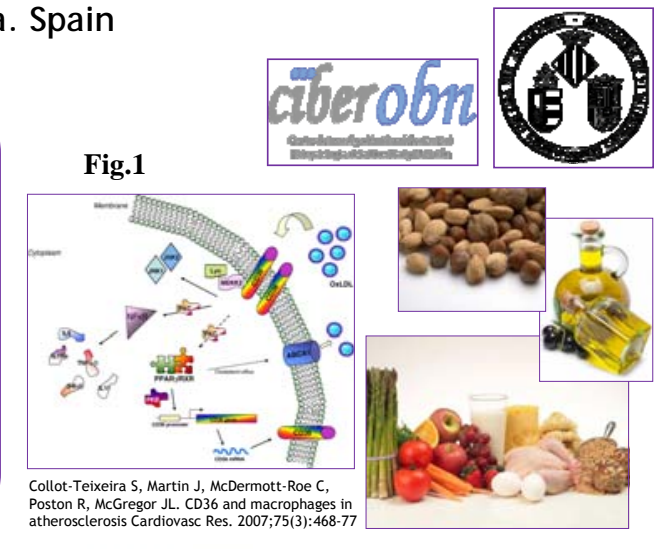

\section{MATERIAL AND METHODS}

We studied 1036 subjects with high CVR participating in the PREDIMED (PREvención Dieta MEDiterránea) study, recruited in Valencia (Fig. 2). Anthropometric data was obtained and plasma FFA were determined. Adherence to MD was evaluated through a validated questionnaire. Individuals were classified according to the score: low adherence $(<9$ points) or high adherence ( $\geq 9$ points).

\section{RESULTS}

Minor allele frequency $(G)$ was 0.427 . A recessive model was considered (A-allele carriers vs GG homozygous). Homozygous GG subjects had higher FFA concentrations than carriers of the A allele (GG: $18.9 \pm 7.8 \mathrm{mg} / \mathrm{dl}$ vs AA+AG: $17.4 \pm 6.7 \mathrm{mg} / \mathrm{dl}, \mathrm{P}=0.035$ ) (Table 1). Interestingly, we observed an interaction ( $\mathrm{P}$-int: 0.049 ) between rs1761667 polymorphism and adherence to the MD in determining FFA concentrations ( $\mathrm{P}$-int $=0.049)$ and body mass index (BMI) ( $\mathrm{P}$ int $=0.019$ ). So, in subjects with low adherence to $M D$, the GG genotype showed higher FFA concentrations (GG: $20.3 \pm 7.8 \mathrm{mg} / \mathrm{dl}$ vs $A A+A G: 17.5 \pm 6.4 \mathrm{mg} / \mathrm{dl}, P=0.001$ ), and $B M I$ (GG: $32.1 \pm 5.6 \mathrm{~kg} / \mathrm{m}^{2}$ vs $A A+A G: 31.0 \pm 5.0 \mathrm{~kg} / \mathrm{m}^{2}$, $\mathrm{P}=0.046$ ) compared with A-allele carriers. But, in subjects with high adherence to $M D$ no significant differences were observed according to genotype in this parameters (FFA: $P=0.702$; $B M I: P=0.555$ )(Fig. 3 and 4).

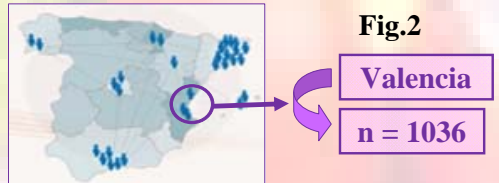

Fig 3: Average FFA concentration according to genotype to rs1761667 in subjects with high and low adherence to MD

$P$ interaction rs1761667*adh. MD $=0.049$

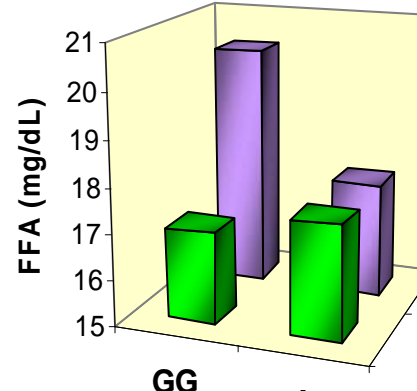

Low adh. High adh.

A

carriers

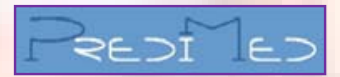

Table 1: Average FFA concentration according to genotype to rs1761667

\begin{tabular}{|c|c|c|c|}
\hline & GG & A-carriers & P \\
\hline FFA $(\mathrm{mg} / \mathrm{dL})$ & $\mathbf{1 8 . 9} \pm 7.8$ & $17.4 \pm 6.7$ & $\mathbf{0 . 0 3 5}$ \\
\hline
\end{tabular}

Fig 4: Average BMI according to genotype to rs1761667 in subjects with high and low adherence to MD

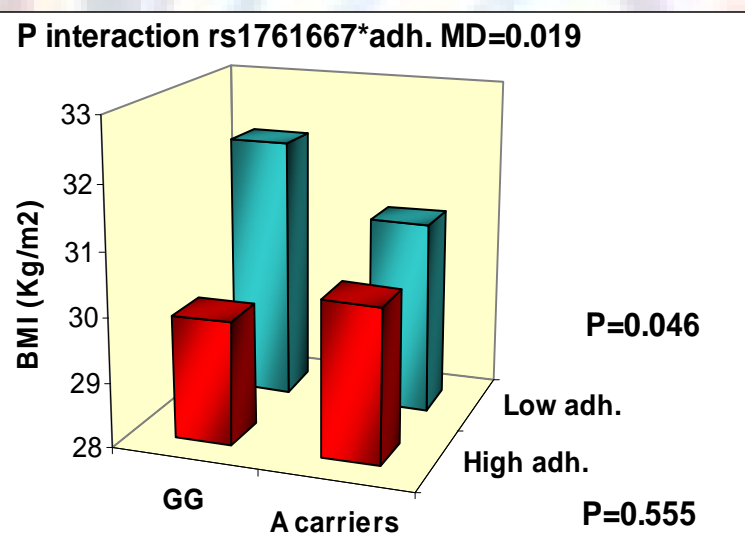

\section{CONCLUSION}

Adherence to MD modulates the effect of the CD-36-rs1761667 polymorphism on FFA concentration and BMI in a high CVR population. 